\title{
EFSUMB Guidelines and Recommendations in Elastography
}

\author{
Report from Meeting in Bologna
}

EFSUMB felt the need to develop a set of Guidelines for the use of elastography, given the growing general interest, number of available techniques and level of scientific evidence in this field, following a process similar to that utilized for CEUS non liver Guidelines already printed and the new Liver Guidelines (with WFUMB) in press. EFSUMB hopes these recommendations will help users and would-be users of elastography to understand the basic principles and limitations of the method and to apply it and successfully interpret the findings across the most commonly used clinical applications.

A meeting was held in Bologna on $7 \& 8$ September to finalise the manuscript. Nearly all the authors were present. The lead authors are David Cosgrove, Fabio Piscaglia and Christoph F Dietrich. The paper comprises of the following sections:
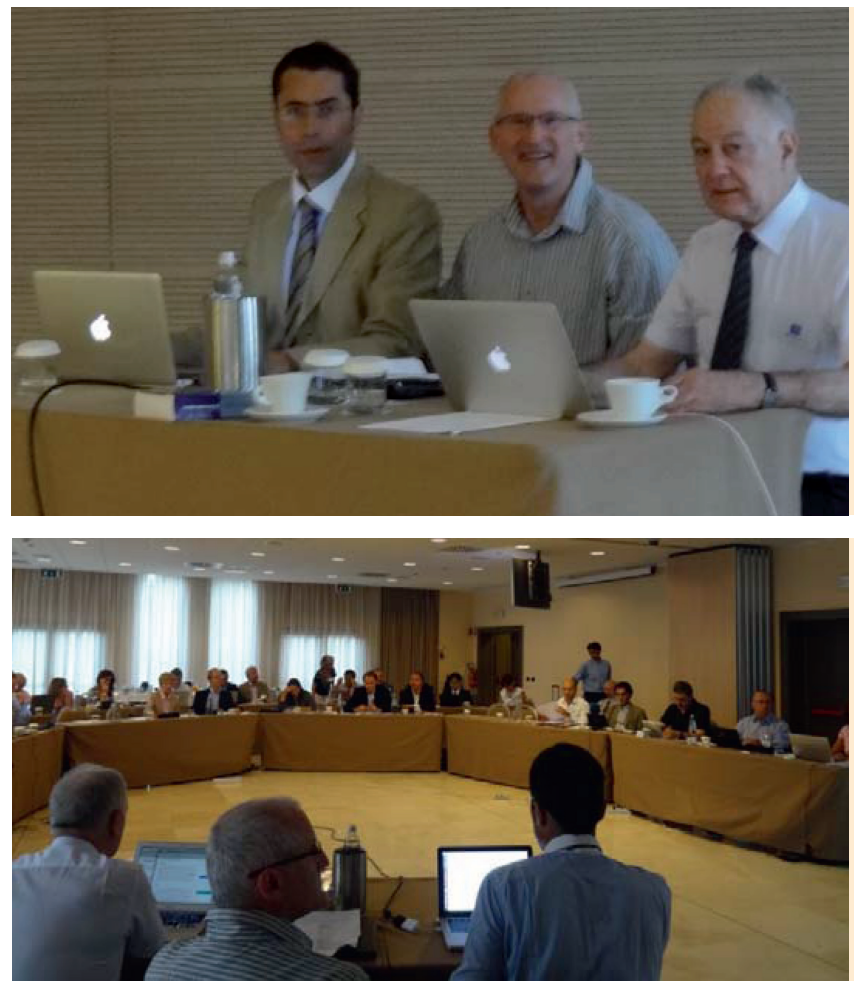

Fabio Piscaglia, EFSUMB President, Christoph F Dietrich, EFSUMB President Elect and David Cosgrove First Author of Elastography Guidelines.

Authors and industry at the Elastography meeting in Bologna September 2012.
- Basic principles of elastography headed by Jeffrey C Bamber

- Liver headed by Ioan Sporea

- Endoscopic Ultrasound Elastography headed by Christoph F Dietrich

- Breast headed by David Cosgrove

- Thyroid headed by Joerg Bojunga

- Prostate headed by Jean-Michel Correas

- Gastro-Intestinal Tract headed by Odd Helga Gilja

- Musculo-Skeletal headed by Andreas Klauser

The co-authors are Fabrizio Calliada, Vito Cantisani, Mirko D’Onofrio, Elena Drakonaki, Mathias Fink, Mireen Friedrich-Rust, Jeremie Fromageau, Roald F Havre, Christian Jenssen, Ralf Ohlinger, Adrian Saftoiu and Fritz Schaefer.

The manuscript looks at clinical applications, clinical potential, pitfalls and limitations, offers practical advice and makes recommendations. It is anticipated that the ePub will be available before the end of the year and the publication in the journal is anticpated in early 2012 either as a single paper or in two parts.

The project was supported by the ultrasound Industry, to whom the authors and EFSUMB are grateful. The industry had, however, no influence in deciding the content of the manuscript, which is solely under the responsibility of the authors. Representatives from BK Medical, Echosens, Esaote, GE, Hitachi, Philips, Siemens, Supersonic and Toshiba attended the meeting and actively participated. 